ISSN 1817-3721, E-ISSN 1818-8745

Plant Tissue Cult. \& Biotech. 28(2): 201-214, 2018 (December)

(CBangladesh Assoc. for Plant Tissue Culture \& Biotechnology

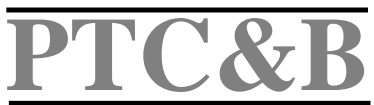

\title{
In vitro Shootlets Multiplication and Callus Proliferation of Jojoba (Simmondsia chinensis) Plant
}

\author{
S.A. Bekheet, A.A. Reda and S.A. Eid \\ Department of Plant Biotechnology, National Research Centre, 33 El Bohouth St., \\ Dokki, 12622, Giza, Egypt
}

Key words: Jojoba, In vitro, Multiplication, Callus proliferation

\begin{abstract}
A protocol for in vitro multiplication and callus proliferation of jojoba was developed. Nodal segments were cultured on MS supplemented with $1 \mathrm{mg} / \mathrm{BA}$. For multiplication, combination of $1.5 \mathrm{mg} / \mathrm{BA}+1 \mathrm{mg} /$ IAA resulted in greater number of shootlet. While, $1 \mathrm{mg} / \mathrm{BA}+\mathrm{NAA}$ enhanced the height of shootlet and number of nodes. Also, the effect of adenine sulfate and TDZ on shootlets multiplication was examined. The maximum number of shootlets emergence was obtained with medium contained $30 \mathrm{mg} \Lambda$ adenine sulfate. Likewise, the used levels of TDZ specially $2 \mathrm{mg} /$ enhanced shootlets proliferation as well as length of shootlet and number of nodes. Callus induction using combinations of NAA or picloram with $\mathrm{BA}$ or $\mathrm{Kn}$ was evaluated. The maximum callus frequency was observed with $5 \mathrm{mg} / \mathrm{BA}+1 \mathrm{mg} /$ picloram followed by $5 \mathrm{mg} / \mathrm{BA}+2 \mathrm{mg} /$ picloram containing medium. It was found that fresh mass and growth value increased gradually till the third subculture.
\end{abstract}

\section{Introduction}

Jojoba (Simmondsia chinensis) plant, is a medicinal and oil-yielding, multi-purpose species of Simmondsiaceae. The oil of jojoba seeds is used in lubricants, cosmetics, and pharmaceutical and as a replacement for sperm oil in manufacturing of inks, vanishes, waxes detergents, reins and plastics. This plant is considered to be drought resistant because it has an extensive and deep root system (Naqvi and Ting 1990). Also, it can be grown on marginal and wasteland due to tolerance of extreme range of temperature from -5 to $54^{\circ} \mathrm{C}$ (Bhardwaj et al. 2010). Because jojoba is a dioecious plant with male and female flowers on separate plants the current method of seed propagation results in a population of

*Author for correspondence: <shawky005@yahoo.com>.

DOI: https://doi.org/10.3329/ptcb.v28i2.39679 
male and female plants, with a slight tendency toward more male plants (Harsh et al. 1987). Female plants are commercially more important for the seed production. However, 8 - 10\% males are necessary for pollination (Reddy and Chikara 2010). Furthermore, high variation is observed in oil content and seed yield due to pollination by wind. Therefore, a suitable method of vegetative propagation is thus needed to develop this plant as a crop, and also to multiply and maintain selected clones with desirable characteristics, such as seed yield, wax content, and disease resistance. Vegetative propagation were used to reproduce jojoba, e.g. layering (Reddy 2003), grafting (Bashir et al.2007), or semi hard wood cuttings (Singh et al. 2003), but the number of propagules is limited by plant size and time of year.

Micropropagation of jojoba plant offers a promising means of commercial mass production of superior clones. A single explant source could conceivably provide thousands of true-to-type plantlets per year i.e., those plants that are genetically similar to the parental stock and that could potentially maintain the genetic line (Bekheet et al. 2015). Moreover, in vitro derived plants grow more vigorously than both seedlings and rooted cuttings (Chaturvedi and Sharma 1989, Reddy and Chikara 2010). In this respect, several reports on in vitro propagation of jojoba appeared in literature using various explants such as auxiliary buds (Chaturvedi and Sharma 1989, Llorente and Apostolo 1998, Tyagi and Prakash 2004, Singh et al. 2008, Bekheet et al. 2015) and shoot tip (Sardana and Batra 1998). Otherwise, culture media containing different concentrations of various growth regulators have been used for in vitro shootlets initiation of jojoba by a number of researchers. Mostly cytokinins (BA, Kn and Zeatin) have been used in combination with auxins (NAA, IAA and IBA) or GA 3 with varying levels of success. However, rates of multiplication and survival were still not sufficient for the efficient micropropagation of jojoba. Incorporation of additives in shoot multiplication medium of jojoba, favored auxiliary effect on shoot growth in the cultures. Combination of cytokinin and adenine is favourable for in vitro shoot formation. On the other hand, the development of an efficient callus proliferation system is a prerequisite for a number of biotechnological interventions for the improvement of jojoba, such as genetic transformation, production of useful metabolites in vitro, etc. In this context, callus induction of jojoba plant were reported using two different types of explants, i.e., immature zygotic embryos, leaf disks and stem explants (Gaber et al. 2007, El-Ashry et al. 2017). The present work aimed at developing an effective protocol for in vitro shoot buds multiplication and callus proliferation of jojoba. 


\section{Materials and Methods}

Nodal segments (approximately $3 \mathrm{~cm}$ long) explants of jojoba taken from plants that were growing at farm of Egyptian Natural Oil Company were used as explants. After removing leaves, the cuttings were thoroughly washed in running tap water for $30 \mathrm{~min}$ and then dipped in ethanol $70 \%$ for $30 \mathrm{sec}$. The explants were then sterilized with Clorox (60\%) and mercuric chloride solution $(0.2 \%)$ for $10 \mathrm{~min}$. After sterilizing, the explants were rinsed in sterilized distilled water (three times) to remove all traces of the disinfectants. All steps of the sterilization producers were achieved under laminar airflow cabinet. The explants were aseptically cultured in tubes $(25 \times 150 \mathrm{~mm})$ containing solidified MS supplemented with $1 \mathrm{mg} / \mathrm{BA}$ (based on results of our preliminary experiments), keeping one explant in a tube. Contaminated cultures were discarded and the differentiated shootlets (Fig. 1a) were used for multiplication and callus proliferation experiments.

In order to examine how combination of BA and NAA or IAA affects shootlets multiplication of jojoba, two concentrations i.e., 1 and $1.5 \mathrm{mg} /$ of $\mathrm{BA}$ in combination with $1 \mathrm{mg} \Lambda$ of NAA or IAA were added to culture medium. Single uniform shootlets $(1 \mathrm{~cm}$ length) were vertically cultured in glass jars containing medium plus different combination of growth regulators.

This experiment was carried out to study the effect of different levels (10, 20, 30 and $40 \mathrm{mg} /$ ) of adenine sulfate (AS) added to starting medium (MS + $1 \mathrm{mg} /$ BA) on multiplication of jojoba shootlets. The proliferated shootlets were divided and single uniform (1 cm length) shootlets were cultured onto AS containing medium. The study included a control (AS-free medium) to form a total of four treatments.

This experiment was designed to study the effects of thidiazuron (TDZ) on in vitro shootlets proliferation of jojoba. Single shootlets $(1 \mathrm{~cm}$ length) were cultured onto MS amended with $1 \mathrm{mg} / \mathrm{BA}$ and three $(1,2$ and $3 \mathrm{mg} /)$ concentrations of TDZ. The experiment was included a control (TDZ-free medium).

For the three experiments of shootlets multiplication, number of shootlets per explant, height of main shootlets $(\mathrm{cm})$ and number of nodes per main shootlet were recorded after six weeks of culturing.

This study was conducted to investigate the effect of auxins i.e., NAA and picloram in combinations with BA and Kn on ability of callus induction from leaf explants of jojoba. Leaf segments $(1-1.5 \mathrm{~cm})$ excided from the in vitro grown shootlets were inoculated onto jars containing MS supplemented with different combinations of NAA and picloram and BA and Kn. Callus frequency (\%) and callus color were recorded after 30 and 45 days of culturing. 
To assess the effect of subculturing on fresh medium on proliferation and growth of jojoba callus, equal inoculum $(0.5 \mathrm{~g})$ of healthy callus were cultured on MS contained $5 \mathrm{mg} \Lambda \mathrm{BA}+1 \mathrm{mg} \Lambda$ picloram. The callus was subcultured at every five weeks interval up to four. Fresh mass, growth value and callus texture were registered at end of each subculturing.

Growth value $=\frac{\text { Final fresh mass }- \text { initial fresh mass }}{\text { Initial fresh mass }}$

All media consisted of MS elements supplemented with 3\% (w $/ N)$ sucrose and $0.7 \%(\mathrm{w} / \mathrm{N})$ agar. Different plant growth regulators combinations were added as previously mentioned. The $\mathrm{pH}$ of the media was adjusted to 5.7 using either $0.1 \mathrm{~N} \mathrm{NaOH}$ or $0.1 \mathrm{~N} \mathrm{HCl}$ prior to adding agar. Media were autoclaved at $121^{\circ} \mathrm{C}$ and $1.05 \mathrm{~kg} / \mathrm{cm}$ for $20 \mathrm{~min}$.

Cultures were normally maintained at $25 \pm 2^{\circ} \mathrm{C}$ and $16 \mathrm{hrs}$ photoperiod provided by white fluorescent tubes (3000 Lux). Each experiment was set up as a separate completely randomized design. Data were statistically analyzed from 15 replicates using standard error (SE) according to the method described by Snedecor and Cochran (1967).

\section{Results and Discussion}

This experiment was set up to determine the effect of cytokinin $\times$ auxin interaction on in vitro shootlets multiplication of jojoba. Individual shootlets were cultured on MS supplemented with two concentrations (1 and $1.5 \mathrm{mg} /$ ) of BA in combination with $1 \mathrm{mg} /$ of NAA or IAA. Generally, BA when combined with IAA gave the best results of shootlet number compared with NAA (Table 1). The combination of $1.5 \mathrm{mg} / \mathrm{BA}+1 \mathrm{mg} \Lambda$ IAA resulted in greater number of shootlet per explant (4.00) (Table 1 and Fig. 1b). However, NAA obviously enhanced the height of main shootlet and number of nodes. The maximum shootlet height $(4.00$ $\mathrm{cm}$ ) and number of nodes (4.20) were obtained when $1 \mathrm{mg} /$ NAA combined with $1 \mathrm{mg} / \mathrm{BA}$ (Table 1). It is also obvious from the coefficient of correlation obtained that the number of nodes per shootlet was positively correlated with the height of main shootlet. These results can be utilized in elongation of propagules before rooting stage.

Both auxin and cytokinin are usually added to tissue culture media in order to obtain morphogenesis. In combination with auxins, cytokinins stimulate cell division even in non-meristematic tissues. In parenchyma, cell division occurs only when both auxins and cytokinins are present. Furthermore, the ratio of cytokinins to auxins controls cell differentiation and when the ratio is in the 
favour of cytokinins, shoot formation takes place (Benzioni et al. 2003). In the present investigation, the media containing BA in combination with NAA proved to be better in effect on height of shootlet and the number of nodes. While, BA with IAA enhanced shootlet number. The results are supported the

Table 1. Effect of BA in combinations with NAA and IAA on in vitro shootlets multiplication of jojoba.

\begin{tabular}{|c|c|c|c|}
\hline Medium & $\begin{array}{l}\text { No. of shootlets/ } \\
\text { explant } \pm \text { SE }\end{array}$ & $\begin{array}{l}\text { Height of main } \\
\text { shootlet }(\mathrm{cm})\end{array}$ & $\begin{array}{l}\text { No. of nodes/main } \\
\text { shootlet } \pm \text { SE }\end{array}$ \\
\hline $\begin{array}{l}\mathrm{MS}+1 \mathrm{mg} \wedge \mathrm{BA}+1 \\
\mathrm{mg} / \mathrm{NAA}\end{array}$ & $3.20 \pm 0.18$ & 4.00 & $4.20 \pm 0.10$ \\
\hline $\begin{array}{l}\mathrm{MS}+1.5 \mathrm{mg} / \mathrm{BA}+ \\
1 \mathrm{mg} / \mathrm{NAA}\end{array}$ & $3.00 \pm 0.21$ & 3.80 & $3.50 \pm 0.12$ \\
\hline $\begin{array}{l}\mathrm{MS}+1 \mathrm{mg} / \mathrm{BA}+ \\
1 \mathrm{mg} \Lambda \text { IAA }\end{array}$ & $3.90 \pm 0.14$ & 3.00 & $3.10 \pm 0.10$ \\
\hline $\begin{array}{l}\mathrm{MS}+1.5 \mathrm{mg} / \mathrm{BA}+ \\
1 \mathrm{mg} / \mathrm{IAA}\end{array}$ & $4.00 \pm 0.11$ & 3.10 & $3.30 \pm 0.21$ \\
\hline
\end{tabular}
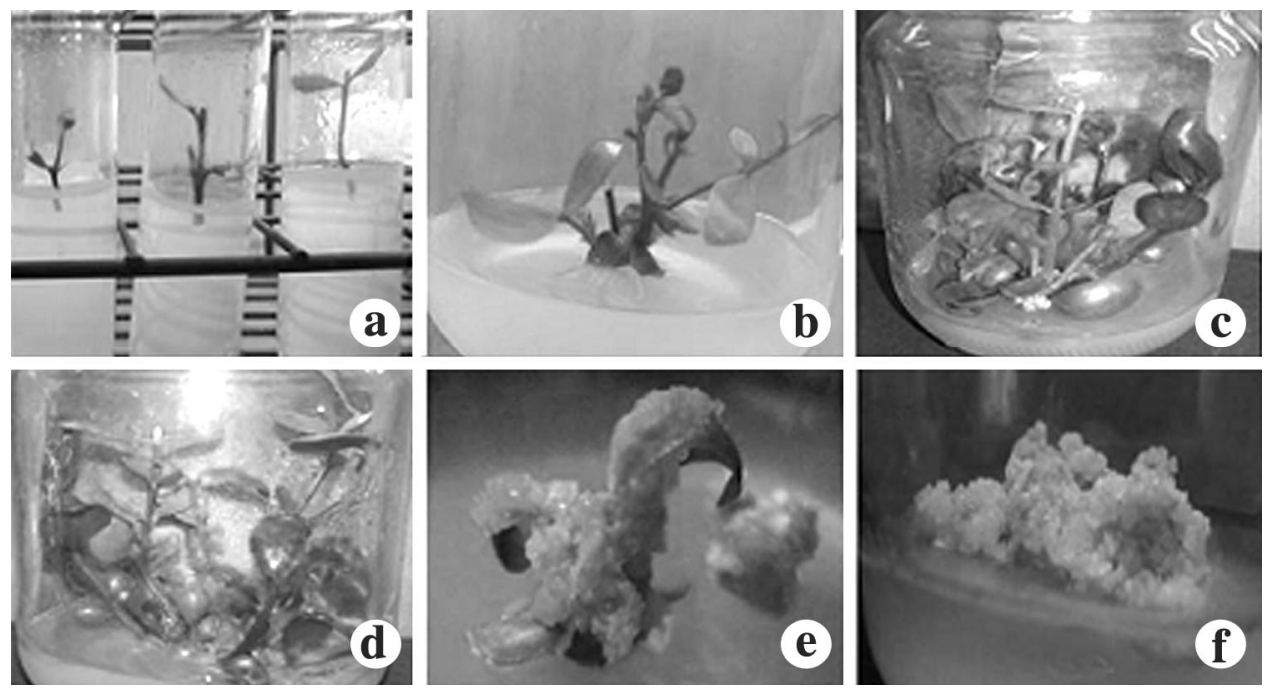

Fig. 1. In vitro shootlets differentiation of jojoba from nodal explants on MS supplemented with1 $\mathrm{mg} /$ BA (a), shootlets multiplication on $1 \mathrm{mg} / \mathrm{BA}+1 \mathrm{mg} /$ IAA containing medium (b), shootlets multiplication on medium contained $1 \mathrm{mg} / \mathrm{BA}+30 \mathrm{mg} /$ adenine sulfate (c), shootlets multiplication on medium contained $1 \mathrm{mg} / \mathrm{BA}+3 \mathrm{mg} / \mathrm{TDZ}(\mathrm{d})$, callus inductionon $5 \mathrm{mg} / \mathrm{BA}+$ $1 \mathrm{mg} /$ picloram containing medium (e) and friable callus obtained at fourth subculture on MS medium contained $5 \mathrm{mg} / \mathrm{BA}+1 \mathrm{mg} /$ picloram (f). 
findings of Scaramuzzi and D'Ambrosio (1988), Sardana and Batra (1998), Kumar et al. (2009), who mentioned that BAP with NAA or IAA was very effective for the in vitro establishment and multiplication of jojoba. Mousa and Bakhashwain (2014) stated that higher concentrations of BAP + IAA were better for shoot formation and multiplication than BAP + NAA. In this respect, Botti and Zunino (1988) used MS containing different concentrations and combinations of BA, NAA and $\mathrm{GA}_{3}$. However, Bashir et al. (2007) reported the use of BA (alone) proved better than BA in combinations with auxins. BA at the rate of $2.5 \mathrm{mg} /$ caused early sprouting of buds that resulted in the longest primary shoot and maximum number of nodes per shoot. While BA at the rate of $5.0 \mathrm{mg} A$ produced the maximum number of shoots per explant. Recently, Öncel and Erişen (2017) mentioned that the highest number of shoots (9.13 shoots per explant) was obtained on MS containing $2.0 \mathrm{mg} / \mathrm{BA}$. The superiority of BA for shoot induction may be attributed to the ability of plant tissues to metabolize BA more readily than other synthetic growth regulators, or to the ability of BA to induce production of natural hormones such as zeatin within the tissue (Malik et al. 2005).

Experiment was conducted to determine the effect of adenine sulfate (AS) on in vitro shootlets multiplication of jojoba. To this, it was added four concentrations (10, 20, 30 and $40 \mathrm{mg} \Lambda$ ) AS and it was included a control (adenine sulfate-free medium). Variations in the response of the explants have been observed in terms of proliferation rate, shoot length and number of nodes. The results indicated that the culture medium supplemented with AS enhanced shootlets formation of jojoba. The maximum number of profuse shootlets emergence (8.5) was observed with medium supplemented with $30 \mathrm{mg} /$ AS (Table 2). Meanwhile, the emergence of shootlets were healthy and light green color (Fig. 1-c). However, the number of shootlets per explants was only 3.10 in absence of adenine sulfate. On the other hand, the highest values of shootlet length (4.50) and number nodes per shootlt (4.20) were registered with medium contained $20 \mathrm{mg} A$ adenine sulfate.

Success of in vitro multiplication of plants depends on the control of morphogenesis which is influenced by several factors, such as tissues or explants, composition of media, plant growth regulators, media additives and culture environment (Rai et al. 2010). Despite the fact that nitrates and ammonium salts have been widely used in the conventional in vitro protocols as nitrogen source, many reports suggest the use of reduced nitrogen forms particularly adenines and amino acids. These additives can adjust the nitrogen utilization of in vitro grown culture by regulating primary nitrogen assimilation and can improve cell proliferation as well as regeneration in many plant species (Shrivastava and 
Banerjee 2008). In the present study, it was demonstrated that the addition of AS stimulated the formation and elongation of in vitro grown shootelts of jojoba. In case of multiple shootlets cultures, MS with 1 BA plus $30 \mathrm{mg} / \mathrm{d}$ of AS proved most effective formulation for shootlets and proliferation than any other concentration tried. At that time the multiple shootlets were healthy with light green color. Out of the four concentrations of AS, $20 \mathrm{mg} / \mathrm{w}$ was found to be prominent in terms of shootlets length and number of nodes per shootlet. The similar effect of addition of the AS for increased shoot multiplication has been reported in jojoba Singh et al. (2008). Sharma and Vimala (2010) mentioned that supplementation of MS with BAP (1.0 $\mathrm{mg} /)$ and AS (0.072 $\mathrm{g} /)$ enhances shoot multiplication of Centella asiatica, from leaf explants up to 11 shoot buds per explant. In this respect, Imran et al. (2012) used AS as an experimental hormone for in vitro production of multiple shoots of Carissa carandas (L.). Recently, Prakasha and Ramya (2017) in their study on the effect of AS on in vitro multiplication of banana, cv. Grand Naine stated that medium containing $40 \mathrm{mg} / \mathrm{AS}$ showed highest multiplication ratio of 2.3 times along with well-formed shoots in $22-25$ days of incubation.

Table 2. Effect of addition of adenine sulfate (AS) on in vitro shootlets multiplication of jojoba.

\begin{tabular}{|c|c|c|c|}
\hline Medium & $\begin{array}{l}\text { No. of shootlet/ } \\
\text { explant } \pm S E\end{array}$ & $\begin{array}{l}\text { Length of main } \\
\text { shootlet }(\mathrm{cm})\end{array}$ & $\begin{array}{l}\text { No. of nodes / main } \\
\text { shootlet } \pm \text { SE }\end{array}$ \\
\hline $\begin{array}{l}\mathrm{MS}+1 \mathrm{mg} \Lambda \mathrm{BA} \\
\text { (control) }\end{array}$ & $3.10 \pm 0.10$ & 2.30 & $1.40 \pm 0.14$ \\
\hline $\begin{array}{l}\mathrm{MS}+1 \mathrm{mg} \Lambda \mathrm{BA}+10 \\
\mathrm{mg} \Lambda \mathrm{AS}\end{array}$ & $5.20 \pm 0.15$ & 4.40 & $4.00 \pm 0.10$ \\
\hline $\begin{array}{l}\mathrm{MS}+1 \mathrm{mg} \Lambda \mathrm{BA}+20 \\
\mathrm{mg} \Lambda \mathrm{AS}\end{array}$ & $7.00 \pm 0.41$ & 4.50 & $4.20 \pm 0.15$ \\
\hline $\begin{array}{l}\mathrm{MS}+1 \mathrm{mg} \Lambda \mathrm{BA}+30 \\
\mathrm{mg} \Lambda \mathrm{AS}\end{array}$ & $8.50 \pm 0.14$ & 4.00 & $3.90 \pm 0.11$ \\
\hline $\begin{array}{l}\mathrm{MS}+1 \mathrm{mg} \Lambda \mathrm{BA}+40 \\
\mathrm{mg} \Lambda \mathrm{AS}\end{array}$ & $6.80 \pm 0.10$ & 3.90 & $3.80 \pm 0.20$ \\
\hline
\end{tabular}

Individual shootlets of jojoba were cultured on MS media containing $1 \mathrm{mg} /$ BA plus 1,2 or $3 \mathrm{mg} A$ thidiazuron (TDZ) in order to increase rate of multiplication. It was found that TDZ played a vital role in adventitious shootlet induction and elongation. The highest number of shootlets per explant (7.50) was exhibited by the combination of $1 \mathrm{mg} / \mathrm{BA}+2 \mathrm{mg} / \mathrm{TDZ}$ (Table 3). While the lowest number (3.20) was obtained on TDZ free medium. Also, the maximum values of shootlet length (4.70) and number of nodes per shootlet (4.30) were 
recorded with medium containing $1 \mathrm{mg} / \mathrm{BA}+2 \mathrm{mg} \Lambda \mathrm{TDZ}$. It was noticed that the highest level of TDZ $(3 \mathrm{mg} /)$ resulted in vitrification of the multiplied shootlets of jojoba (Fig. 1d).

Table 3. Effect of TDZ on in vitro shootlets multiplication of jojoba.

\begin{tabular}{|c|c|c|c|}
\hline Medium & $\begin{array}{c}\text { No. of shootlets/ } \\
\text { explant } \pm \text { SE }\end{array}$ & $\begin{array}{c}\text { Length of main } \\
\text { shootlet }(\mathrm{cm})\end{array}$ & $\begin{array}{c}\text { No. nodes/main } \\
\text { shootlet } \pm \text { SE }\end{array}$ \\
\hline $\begin{array}{l}\mathrm{MS}+1 \mathrm{mg} / \mathrm{BA} \\
\text { (control) }\end{array}$ & $3.20 \pm 0.18$ & 2.10 & $1.30 \pm 0.20$ \\
\hline $\begin{array}{l}\mathrm{MS}+1 \mathrm{mg} / \mathrm{BA}+ \\
1 \mathrm{mg} / \mathrm{TDZ}\end{array}$ & $6.10 \pm 0.17$ & 4.50 & $3.90 \pm 0.15$ \\
\hline $\begin{array}{l}\mathrm{MS}+1 \mathrm{mg} / \mathrm{BA}+ \\
2 \mathrm{mg} / \mathrm{TDZ}\end{array}$ & $7.50 \pm 0.30$ & 4.70 & $4.30 \pm 0.25$ \\
\hline $\begin{array}{l}\mathrm{MS}+1 \mathrm{mg} / \mathrm{BA}+ \\
3 \mathrm{mg} / \mathrm{TDZ}\end{array}$ & $6.60 \pm 0.19$ & 4.10 & $4.00 \pm 0.11$ \\
\hline
\end{tabular}

Thidiazuron (TDZ) has been found to mimic cytokinin-like activity to break dormancy of lateral buds (Wang et al. 1986) and to induce in vitro shoot formation (Faisal and Anis 2006). It has also been reported as a potential plant growth regulator to induce a high frequency of shoot regeneration, particularly in woody plant species (Huetteman and Preece 1993). The current results demonstrated that the addition of TDZ had positive effect on jojoba shootlets multiplication. Maximum number of shootlets with their greatest length was obtained when $2 \mathrm{mg} \Lambda \mathrm{TDZ}$ added to $1 \mathrm{mg} / \mathrm{BA}$ containing medium. The results were found to be in agreement with those reported by Mohamed et al. (2017). In their study on in vitro shoot regeneration of jojoba, they found that the presence of TDZ in initiation medium increased the rate of explants with sprouting buds. They added, the highest number of shoots per explants was obtained when 2.5 $\mathrm{mg} / \mathrm{BA}$ and $5 \mathrm{mg} / \mathrm{TDZ}$-exposed explants were subcultured for 6 weeks on medium containing $1 \mathrm{mg} / \mathrm{BA}$. Singh and Agarwal (2016) mentioned that the best axillary shoot bud induction of jojoba was observed on MS supplemented with $4.6 \mu \mathrm{M}$ TDZ with 5 shoot buds per explant. In the shoot cluster, which was subcultured on MS supplemented with $2.3 \mu \mathrm{M}$ TDZ, the rate of shoot multiplication increased in the 3rd subculture. In this respect, in preliminary studies on the effect of TDZ on the proliferation of adventitious buds of banana, Lee (2001) stated that the optimal concentration of TDZ (tissue culture grade) was $0.2 \mathrm{mg} /$ for the cultivars 'Pei Chiao' (AAA) and Latundan (AAB). In later experiments, when BA (4.0 $\mathrm{mg} \Lambda)$ was used in combination with TDZ, results again indicated that the optimal concentration of TDZ was $0.2 \mathrm{mg} \Lambda$. 
Leaf explants of jojoba were examined for their ability to induce callus using NAA and picloram in combinations of BA and $\mathrm{Kn}$ as growth regulators. The response of different combinations to callus induction is shown in Table 4. Results obtained reveal that there was great effect of growth regulator combination on callus induction of jojoba. The explants developed callus within 30 days and callus growth was increased after 45 days of culturing. Generally, picloram in combination with $\mathrm{BA}$ or $\mathrm{Kn}$ stimulates callogenesis from leaf explants more than NAA. The maximum callus frequency $(80 \%)$ with healthy morphology was observed with $5 \mathrm{mg} / \mathrm{BA}+1 \mathrm{mg} \Lambda$ picloram followed by $5 \mathrm{mg} \Lambda$ $\mathrm{BA}+2 \mathrm{mg} \Lambda$ picloram containing medium (Table 4 and Fig. 1e). There was no callus formed on MS supplemented with $5 \mathrm{mg} / \mathrm{BA}+0.5 \mathrm{mg} /$ NAA. Different colors and textures of calli were observed depending on type and concentrations of growth regulators added to culture medium (Table 4).

Table 4. Effect of NAA and picloram in combinations of BA and $\mathrm{Kn}$ on callus induction from leaf explants of jojoba.

\begin{tabular}{lcccl}
\hline \multirow{2}{*}{ Treatment } & \multicolumn{2}{c}{ After 30 days } & \multicolumn{2}{c}{ After 45 days } \\
\cline { 2 - 5 } & $\begin{array}{c}\text { Callus } \\
\text { frequency }(\%)\end{array}$ & $\begin{array}{c}\text { Color of } \\
\text { callus }\end{array}$ & $\begin{array}{c}\text { Callus } \\
\text { frequency }(\%)\end{array}$ & $\begin{array}{l}\text { Color of } \\
\text { callus }\end{array}$ \\
\hline $5 \mathrm{mg} / \mathrm{BA}+0.5 \mathrm{mg} / \mathrm{NAA}$ & 0.0 & - & 0.0 & - \\
$5 \mathrm{mg} / \mathrm{BA}+1 \mathrm{mg} / \mathrm{NAA}$ & 0.0 & - & 20 & Creamy \\
$5 \mathrm{mg} / \mathrm{Kin}+0.5 \mathrm{mg} / \mathrm{NAA}$ & 40 & Creamy & 45 & Creamy \\
$5 \mathrm{mg} / \mathrm{Kin}+1 \mathrm{mg} / \mathrm{NAA}$ & 55 & Creamy & 55 & Brownish \\
$5 \mathrm{mg} / \mathrm{BA}+1 \mathrm{mg} /$ picloram & 75 & Creamy & 80 & Creamy green \\
$5 \mathrm{mg} / \mathrm{BA}+2 \mathrm{mg} /$ picloram & 60 & Creamy & 65 & Brownish \\
$5 \mathrm{mg} / \mathrm{Kn}+1 \mathrm{mg} /$ picloram & 30 & Creamy & 40 & Creamy \\
$5 \mathrm{mg} / \mathrm{Kn}+2 \mathrm{mg} /$ picloram & 40 & Creamy & 45 & Brownish \\
\hline
\end{tabular}

Callus initiation is affected by the explant and type and concentration of growth regulators (PGRs) added to culture media. The most predominant element that eventually regulated the frequency of callogenesis is the type of PGRs and their concentrations. Quite a few auxin and cytokinin sources were used, either alone or in combinations to ensure effective morphogenetic response. The present investigation, out of different combinations of PGRs, 5 $\mathrm{mg} / \mathrm{BA}+1 \mathrm{mg} /$ picloram was found optimum for callus induction of jojoba from leaf explants. On this medium, the percentage of callus induction was 80 and the morphogenic response of observed callus was light green in color with soft texture. Similar findings were reported by El-Ashry et al. (2017). They reported that MS supplemented with $0.5 \mathrm{mg} / \mathrm{BA}+0.5$ or $1 \mathrm{mg} /$ picloram was 
the best treatment to obtain friable calli from leaf explants of jojoba. However, Bala et al. (2015) mentioned that leaf explants of jojoba cultured on MS medium with $1.0 \mathrm{mg} / 2$,4-D alone produced the highest frequency of callus compared with $1.5 \mathrm{mg} /$ IBA. Maximum proliferation of callus was observed on MS containing a combination of $1.0 \mathrm{mg} / 1$ 2,4-D with $0.5 \mathrm{mg} / \mathrm{BAP}$. Sardana and Batra (1998) produced callus from leaf explants of jojoba on MS + $1.0 \mathrm{mg} / \mathrm{NAA}$ and 3.0 or $5.0 \mathrm{mg} / \mathrm{BAP}$. In their study, on callus induction of jojoba, Kumar et al. (2013) obtained higher per cent of callus proliferation (97.3) from leaf explant, taken from field grown mature plant, when cultured on MS supplemented with 2,4-D (2 mg 1$)+$ BA $(0.5 \mathrm{mg} \Lambda)$ within 20 - 22 days of inoculation. On the other hand, callus induction from various explants has also been reported by Arce and Jordan (1988) in jojoba plant. The callus formation was $100 \%$ when nodal segments were cultured on MS + $0.1 \mathrm{mg} / \mathrm{BAP}+0.3 \mathrm{mg} / \mathrm{NAA}+0.01 \mathrm{mg} / \mathrm{GA}_{3}$. Callus was also produced by Rossi (1996) from the nodal segments of jojoba on $\mathrm{MS}+10 \mathrm{mg} / \mathrm{BA}$ or $\mathrm{Kn}$ alone or in combination with $0.2 \mathrm{mg} / \mathrm{IBA}$.

After callus induction, the callus is grown further on a new medium. The time interval for subculturing is calculated according to the growth pattern of the particular tissue type and genotype of the plant. This experiment was carried out to study the effects subculturing on growth and proliferation of callus cultures of jojoba. The fragments of granular calli, developed from leaf explant were cultured on MS contained $5 \mathrm{mg} / \mathrm{BA}+1 \mathrm{mg} /$ picloram and they were subcultured for four times (five weeks interval) on fresh medium. The results obtained indicated that the growth parameters were significantly affected by subculturing of callus on fresh medium. Fresh mass and growth value increased gradually till the third sub-culture which registered the highest fresh mass (6.40 g) and highest growth value (11.80). The amount of callus was reduced at the fourth subculture but still about two times of initial inoculum (Table 5). Regarding callus texture, it was hard and compact at the first and second subcultures. Meanwhile callus became soft and friable at the third and fourth subcultures (Table 5 and Fig. 1f).

Table 5. Effect of subculturing on fresh mass, growth value and morphology of jojoba callus cultures.

\begin{tabular}{lccc}
\hline $\begin{array}{l}\text { Number of } \\
\text { subculture }\end{array}$ & $\begin{array}{c}\text { Fresh mass } \\
(\mathrm{g}) \pm \mathrm{SE}\end{array}$ & $\begin{array}{c}\text { Growth } \\
\text { value }\end{array}$ & $\begin{array}{c}\text { Callus } \\
\text { texture }\end{array}$ \\
\hline First & $2.30 \pm 0.20$ & 3.60 & Compact \\
Second & $4.20 \pm 0.15$ & 7.40 & $"$ \\
Third & $6.40 \pm 0.25$ & 11.80 & Friable \\
Fourth & $5.20 \pm 0.11$ & 9.40 & $"$ \\
\hline
\end{tabular}


Callus culture represents clumps of unorganised parenchyma tissue formed through vigorous proliferation by cell division from any kind of explants under cultural condition, showing no polarity. It is essential to maintain the callus cultures in suitable medium to endure the viability of callus for long period of time. For this purpose, callus is transferred to fresh medium, usually consisting of same composition (Samantaray et al. 1995). Moreover, repeated subculturing on fresh agar medium may improve the amount and friability of the callus. In the present study, we found that callus growth presented as fresh mass could grow fast when it was subcultured and tamed several times. Further, callus became friable from the third subculture which could be ideal for preparation of cell suspension cultures. Our results are accordance with those of El-Ashry et al. (2017) who mentioned that maintaining of callus cultures of jojoba by subculturing on fresh medium gives high fresh weight and growth value of friable callus. In this respect, $\mathrm{Li}$ and $\mathrm{Qu}$ (2004) maintained undifferentiated callus of common Bermuda grass [Cynodan dactylon (l) Pers] for a long period (14 months) during subculture in media supplemented with an elevated BAP conc. at $2.2 \mu \mathrm{M}$. Kiah et al. (2012) mentioned that light green friable calli of Artemisia annua L. at the fourth subculture cycle were chosen as the best callus age to initiate cell suspension culture. The cells could be maintained with a growth index of between 10 and 18 for 33 subculture cycles with 16 days interval per cycle.

\section{Acknowledgments}

Authors gratefully acknowledge National Research Center, Egypt, for the financial support through in-house project (No.10060115). The authors also thank Engineer/ Nabil El Mogy (Chairman of Egyptian Natural Oil Company) who provided plants of jojoba.

\section{References}

Arce P and Jordan M (1988) Evaluation of regenerative responses in explant of jojoba (Simmondsia chinensis Link) cultured in vitro using cuttings. Simiente 58: 1-2.

Bala R, Beniwal VS and Laura JS (2015) An efficient and reproducible indirect shoot regeneration from female leaf explants of Simmondsia chinensis, a liquid-wax producing shrub. Physiol. Mol. Biol. Plants 21(2): 293-299.

Bashir MA, Rashid H and Anjum MA (2007) In vitro shoot multiplication of six promising strains of jojoba (Simmondsia chinensis). Biotechnology 6: 309-315.

Bekheet SA, Gabr AM, Reda AA and El-Bahr MK (2015) Micropropagation and assessment of genetic stability of in vitro raised jojoba (Simmondsia chinensis Link) plants using SCoT and ISSR markers. Plant Tissue Culture and Biotechnology 25 (2): 165-179. 
Benzioni A, Mills D, Wenkart S and Zhou Y (2003) Effects of ventilation on the performance of jojoba (Simmondsia chinensis) clones: Multiplication stage. Acta Hort. 616: 135-138.

Bhardwaj M, Uppal S, Jain S, Kharb P, Dhillon R and Jain RK (2010) Comparative assessment of ISSR and RAPD marker assays for genetic diversity analysis in jojoba [Simmondsia chinensis (Link) Schneider] J. Plant Biochem. Biotechnol. 19: 255-258.

Botti C and Zunino C (1988) In vitro micropropagation of jojoba (Simmondsia chinensis). Simiente 58(1-2): 11.

Chaturvedi HC and Sharma M (1989) In vitro production of cloned plants of jojoba (Simmondsia chinensis (Link) Schneider) through shoot proliferation in long-term culture. Plant Sci. 63: 199-207.

El-Ashry AA,GabrAM and Bekheet SA (2017) Zeatin and thidiazuron induced embryogenic calli from in vitro leaf and stem of jojoba (Simmondsia chinensis). Pak. J. Biol. Sci. 20 (7) :355-364.

Faisal M and Anis M (2006) Thidiazuron induced high frequency axillary shoot multiplication in Psoralea corylifolia. Biol. Plantarum 50(3): 437-444.

Gaber A, El-Maraghy HMM, Aly MAM, Nahed AK, Rashed NK and Gamal El-Din AY (2007) Induction of somatic embryogenesis and DNA fingerprinting of Jojoba. Arab J. Biotech. 10(2): 341-354..

Harsh LN, Tewari JC, Patwal DS and Meena GL (1987) Package and practices for cultivation of jojoba Simmondsia chinensis in arid zone. Jodhpur, India: Central Arid Zone Research Institute.

Huetteman CA and Preece JE (1993) Thidiazuron a potent cytokinin for woody plant tissue culture. Plant Cell and Tiss. Org.Cult. 33: 105-119.

Kiah Yann L, Jelodar NB and Lai-Keng C (2012) Investigation on the effect of subculture frequency and inoculum size on theartemisinin content in a cell suspension culture of Artemisia annua L. Aust. J. Crop Sci. 6: 801-807.

Kumar S, Singh N and Mangal M (2009) Micropropagation of Simmondsia chinensis (Link) Schneider through enhanced axillary branching from nodal segments. J. Plant Biol. 36: 75-81.

Kumar S, Mangal M, Dhawan AK and Singh N (2013) Callus induction and plant regeneration of jojoba [Simmondsia chinensis (Link) Schneider]. Indian J. Biotechnology 12: 544-547.

LI L and QU R (2004) Development of highly regenerable callus lines and biolistic transformation of turf-type common Bermuda grass (Cynodan dactylon (L.) Pers. Plant Cell Reports 22: 403-407.

Imran MA, Begum G, Sujatha K and Mallaiah B (2012) Effect of adenine sulphate (Ads) with cytokinins on multiple shoot production in Carissa carandas (L.). International Journal of Pharma and Bio Sciences 3(1): 473-480.

Lee SW (2001) Thidiazuron in the improvement of banana micropropagation. The Second International Symposium on Biotechnology of Tropical and Subtropical Species. 5-9 Nov. Taipei, Taiwan, Republic of China. pp. 1-11. 
Llorente B and Apostolo NM (1998) Effect of different growth regulators and genotype on in vitro propagation of jojoba. New Zeal. J. Crop Hort. Sci. 26: 55-62.

Malik SK, Chaudhury R and Rajwant KK (2005) Rapid in vitro multiplication and conservation of Garcinia indica: A tropical medicinal tree species. Sci. Hort. 106(4): 539-553.

Mohamed T, Tsuchimoto S, Sakai H, Wada N and Fukui K (2017) High-frequency shoots regeneration of an oil crop, Simmondsia chinensis (Link) Schneider using axillary buds. Trop. Agrcult. Develop. 61(1): 15-22.

Mousa MAA and Bakhashwain AAS (2014) Genotypic and growth regulator combination effects on in vitro nodal segments of jojoba (Simmondsia chinensis (Link). Life Science Journal 11(4): 37-42.

Naqvi HH and Ting IP (1990) Jojoba, unique liquid wax produces from the American desert. In: Janick J, Simen JE, editors. Advances in new crops. Portland: Climber Press. pp. 247-251.

Öncel Z and Erişen S (2017) Clonal propagation of jojoba by in vitro culture and determination of sexuality of the regenerants. The journal of Animal \& Plant Science 27(2): 567-574.

Prakasha DP and Ramya G (2017) Effect of adenine sulphate, agar and light on in vitro multiplication of banana cv. Grand Naine (AAA).The Bioscan. 12(1): 205-208.

Rai MK, Asthana P, Jaiswal VS and Jaiswal U (2010) Biotechnological advances in guava (Psidium guajava L.): Recent development and prospects for future research. Trees. 24: $1-12$.

Reddy YN (2003) Effect of different concentration of auxins on rooting and root characters of air and ground layers of jojoba (Simmondsia chinensis (Link) CK Schneider). Ethiop. J. Sci. 26: 155-159.

Reddy MP and Chikara J (2010) Biotechnology advances in jojoba (Simmondsia chinensis). In: Ramawat KG (ed) Desert plants. Springer, Berlin. pp. 407-421.

Rossi C (1996) Rooting and acclimatization of micropropagated jojoba seedlings. Proceedings of the Ninth International Conference on new industrial crops and products, pp. 25-30.

Samantaray S, Rout GR and Das P (1995) An in vitro study on organogenesis in Tremaorientalis. Plant Science 15: 87-94.

Sardana J and Batra A (1998) In vitro propagation of Jojoba (Simmondsia chinensis): A plant of high potential. Adv. Plant Sci. 11: 143-146.

Scaramuzzi F and D'Ambrosio A (1988) Organogenesis and propagation in vitro of Simmondsia chinensis (Link) Schn (jojoba) from vegetative fragments. Acta Hort. 227:411-413.

Sharma S and Vimala Y (2010) Adenine sulphate enhanced in vitro shoot regeneration in Centellaasiatica (L.) urban. J. Indian Bot. Soc. 89(1\&2): 30-33.

Shrivastava S and Banerjee $\mathbf{M}$ (2008) In vitro clonal propagation of physic nut (Jatrophacurcas L.): influence of additives. Int. J.Integ. Biol. 3: 73-79. 
Singh A and Agarwal PK (2016) Enhanced micropropagation protocol of ex vitro rooting of a commercially important crop plant Simmondsia chinensis (Link) Schneider. Journal of Forest Science 62(3): 107-115.

Singh A, Reddy M and Patolia J (2008) An improved protocol for micropropagation of elite genotypes of Simmondsia chinensis (Link) Schneider. Biologia Plantarum. 52: 538542.

Singh KJ, Nayyar H, Dutta A and Dhir KK (2003) Rhizogenetic studies of jojoba: Hormone effect, rooting medium and seasonal variation. Ind. Forester. 129: 14051411.

Snedecor GW and Cochran WG (1967) Statistical methods. 6th Edition. Iowa Stat. University Press, Iowa.

Tyagi RK and Prakash S (2004) Genotypes and sex specific protocols for in vitro micropropagation and medium term conservation of jojoba. Biologia Plantarum. 48(1): 19-23.

Wang SY, Steffens GL and Faust M (1986) Breaking bud dormancy in apple with plant bioregulator, thidiazuron. Phytochemistry 25: 311-317. 